\title{
Current Distortion Evaluation in Traction 4Q Constant Switching Frequency Converters
}

\author{
M. BRENNA ${ }^{1}$, F. FOIADELLI ${ }^{1}$, M. ROSCIA ${ }^{2}$, D. ZANINELLI ${ }^{1}$ \\ ${ }^{1}$ The Politecnico di Milano-Department of Energy, Milano, Italy; ${ }^{2}$ Department of Tecnologie e Progettazione, Università di Bergamo, \\ Bergamo, Italy. \\ Email: \{morris.brenna, federica.foiadelli, dario.zaninelli\}@polimi.it, cristina.roscia@unibg.it
}

Received April 14 ${ }^{\text {th }}, 2009$; revised July $13^{\text {th }}$, accepted August $2^{\text {nd }}, 2009$.

\begin{abstract}
The paper deals with the power quality analysis of interlaced four quadrant (4Q) converters with constant switching frequency. These are in fact the input stages of the locomotives and high speed trains supplied by $25 \mathrm{kV}, 50 \mathrm{~Hz}$ and 15 $\mathrm{kV}, 16.7 \mathrm{~Hz}$ lines. Due to the high power needed for the trains circulation, the $4 Q$ converter can absorb distorted currents, whose harmonic content can affect the signaling systems and communication devices. The presence of more converters gives the opportunity, using dedicated commutation strategy, to interlace them in order to reduce the harmonic content in the absorbed current. In the paper a suitable model of more $4 Q$ converters is developed. The control logic implemented in the model allows the evaluation of the harmonic contribution of both single converter and the interlaced configuration. The analysis is carried out through electromagnetic transient simulations.
\end{abstract}

Keywords: Four Quadrant (4Q) Converter, Interlacing, Traction Systems, Power Quality Analysis, Commutation Strategy

\section{Introduction}

The four quadrant converter (4Q) is the actual best choice to supply the DC voltage link from AC power contact line. A typology of distributed power high speed electric trains having as input stages more 4Q converters [1] has been considered.

The presence of more converters is necessary to guarantee a good redundancy in case of failure and gives the opportunity, using dedicated control logics, to interlace them in order to reduce the harmonic content of the absorbed current. The high power requested by the train for its acceleration in starting phase and for the auxiliary services needs high power converters that do not allow high switching frequencies. Consequently the absorbed current presents a high ripple value characterized by high harmonic current components that cannot be tolerated by the system. Indeed the track circuit used for signaling and communication for the traffic management and safety employs signal currents overlapped with the power ones. These currents can have low frequencies $(50 \mathrm{~Hz}$ and 178 $\mathrm{Hz}$ ) in the traditional signaling system, or they are in the audio frequencies range for the new European ERTMS/ETCS one. Therefore, the harmonics produced by the $4 \mathrm{Q}$ converter can disturb the communications of the track circuit, degrading the safety of the trains circu- lation. On the other hand the 4Q converter has the main benefit to give a nearly sinusoidal line current in both directions of energy flow and the mitigation of reactive power drawn from the line. In fact the $4 \mathrm{Q}$ converter is based on the use of forced commutation switches (GTO, IGBT) and presents a sinusoidal current absorption in phase with the contact line voltage. Moreover, this converter is intrinsically bidirectional and then it can be used both for traction and regenerative braking phases.

The aim of this paper is an analysis of the current absorbed by the high speed trains through a suitable model of more 4Q converters. Thanks to a control logic applied in this work, it is possible to interlace two or more converters in order to evaluate the harmonic contribution of both single converter and the interlaced configuration. The simulation results obtained with an electromagnetic analysis will be presented.

\section{Mathematical Model of the 4Q Converter}

The principle scheme reported in Figure 1 shows how the four-quadrant converter is structurally equal to a single phase voltage source inverter and employs the same switches used for the motor drives. This is an advantage 
because the various branches can have a modular construction [2]. The system includes:

- he transformer secondary side;

- four switches (GTO or IGBT), $\mathrm{T}_{1} \div \mathrm{T}_{4}$;

- four freewheeling diodes $\mathrm{D}_{1} \div \mathrm{D}_{4}$;

- a DC link with capacitive middle circuit $\mathrm{C}$ between the terminals $\mathrm{AK}$ and working at the imposed voltage $V_{d}=$ cost;

- a second harmonic filter $\mathrm{L}_{2}-\mathrm{C}_{2}$ placed downstream the main bridge, tuned to a frequency $f_{2}=2 \cdot f_{1}$ double to the line one.

The system has two main purposes. The first one is the absorption from the contact line, at a voltage $e_{1}$ and frequency $f_{l}$, of a current having the fundamental harmonic $i_{1}$ in phase with $e_{1}$ and with low harmonic content, in order to respect the following conditions:

$$
\begin{array}{ll}
\cos \varphi_{1}=1 & \text { power factor } \\
\lambda \sim 1 & \text { distortion factor }
\end{array}
$$

The second purpose is the absorption from the line of a power with a mean value $P_{l}$, pulsing at the frequency $2 \cdot f_{l}$ and the supply of the three-phase motor drive inverters connected to the dc link with a continuous power $P_{d}$.

In order to study the behaviour of this converter, the modelling process starts by a mathematical representation of the discrete operation modes of the converter. The discrete model describes each working mode through separate equations. Figure 2 shows a simplified representtation of the two-level converter from which the discrete model is derived.

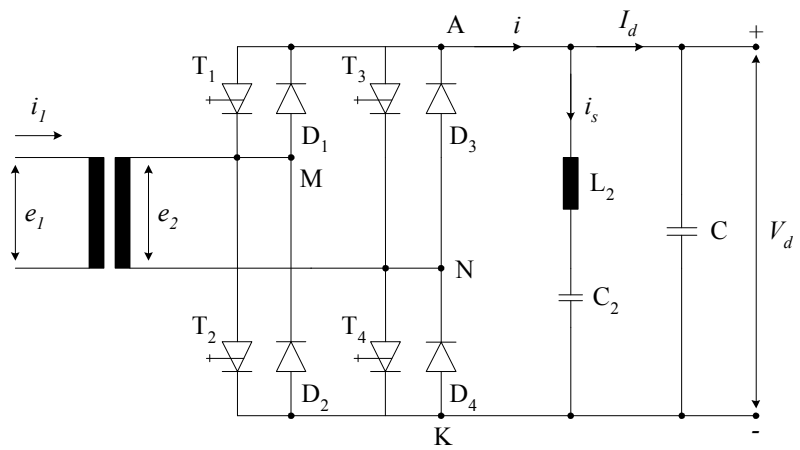

Figure 1. Principle scheme of a four-quadrant converter. $e_{1}=$ line voltage at a frequency $f_{1} ; i_{1}=$ line current

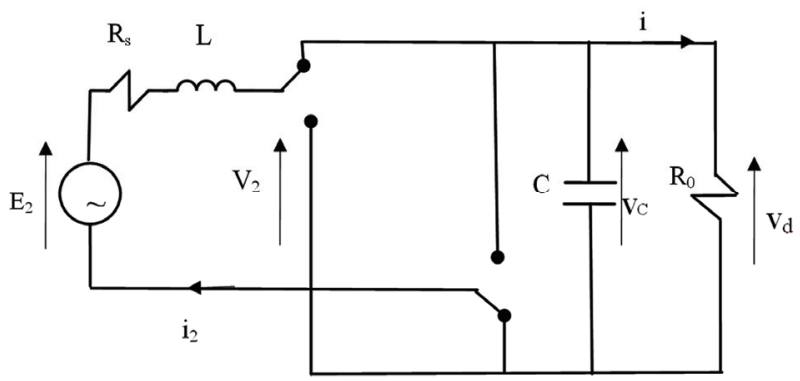

Figure 2. Equivalent circuit of a four-quadrant converter
In the equivalent circuit of Figure 2, the transformer secondary side is represented by:

- an ideal voltage generator $\left(e_{2}=e_{1} / h\right.$, where $h$ is the transformer ratio);

- an inductance $L$, equivalent to the leakage transformer one;

- $\quad a$ resistances $\mathrm{R}_{\mathrm{s}}$ mainly due to the switches;

- load resistances $\mathrm{R}_{0}$;

- DC link capacitance C.

Considering the state variables $i_{s}$ and $v_{c}$, the converter state equations are the following:

$$
\begin{aligned}
& L \frac{d i_{2}}{d t}=-R_{s} i_{2}-v_{c}+E_{2} \sin (\omega t) \\
& C \frac{d v_{C}}{d t}=i_{2}-\frac{v_{C}}{R_{0}}
\end{aligned}
$$

where $\omega$ is the angular frequency. Rewriting these equations in matricial format, it comes out:

$$
\left(\begin{array}{ll}
L & 0 \\
0 & C
\end{array}\right) \frac{d}{d t}\left(\begin{array}{c}
i_{2} \\
v_{C}
\end{array}\right)=\left[\begin{array}{cc}
-R_{s} & -1 \\
1 & -1 / R_{0}
\end{array}\right]\left(\begin{array}{c}
i_{2} \\
v_{C}
\end{array}\right)+\left[\begin{array}{c}
E_{2} \sin (\omega t) \\
0
\end{array}\right]
$$

or $Z \cdot \dot{x}=A \cdot x+E$ where $x$ is the state vector and $\dot{x}$ is its time derivative.

Taking into account that the converter is a two level type, there is another possible operation mode, described by the following matrix $\mathrm{A}$ :

$$
A=\left[\begin{array}{cc}
-R_{s} & 1 \\
-1 & -1 / R_{0}
\end{array}\right]
$$

Looking at the matrix A, it is possible to note that in these two operation modes the first element of the first row and the second one of the second row are the same. Therefore, the state equation can be rewritten to:

$$
\left(\begin{array}{ll}
L & 0 \\
0 & C
\end{array}\right) \dot{x}=\left[\begin{array}{cc}
-R_{s} & -\xi \\
\xi & -1 / R_{0}
\end{array}\right] x+\left[\begin{array}{c}
E_{2} \sin (\omega t) \\
0
\end{array}\right]
$$

where $\xi$ depends from the operation mode and can assumes the value 1 or -1 .

In this analysis, the switches resistance $R_{S}$ has been neglected.

The transformer leakage reactance depends by the contact line frequency:

$$
X=\omega_{1} \cdot L=2 \cdot \pi \cdot f_{1} \cdot L
$$

and it causes a lagging phase shift of an angle $\psi$ between the converter voltage $V_{2}$ and the supply one $\underline{E_{2}}$. Therefore the first harmonic component of voltages and current become:

$i_{2}=\sqrt{2} \cdot I_{2} \cdot \sin \left(\omega_{1} \cdot t\right), e_{2}=\sqrt{2} \cdot E_{2} \cdot \sin \left(\omega_{1} \cdot t\right), v_{2}=\sqrt{2} \cdot V_{2} \cdot \sin \left(\omega_{1} \cdot t-\psi\right)(7)$

where the rms value of the AC voltage $v_{2}$ is related to the DC one $V_{d}$ through a proportional coefficient: 


$$
V_{2}=\frac{E_{2}}{\cos \psi}=k \cdot V_{d}
$$

The DC link voltage of the single-phase converter has a significant ripple component at twice the supply frequency. In fact, as it is possible to note in Figure 1 and reported in [3], the current $i$ given by the 4Q converter to the middle circuit is composed by two components:

$$
i=I_{d}-i_{s}
$$

where:

$$
I_{d}=k \cdot I_{2} \cdot \cos (\psi)=\frac{k \cdot E_{2}}{X} \cdot \sin (\psi)
$$

is the direct component of the $i(t)$ responsible of the power absorption, and

$$
i_{s}=k \cdot I_{2} \cdot \cos \left(2 \cdot \omega_{1} \cdot t-\psi\right)
$$

is an harmonic at the frequency $f_{2}=2 \cdot f_{1}$, with the following rms value:

$$
I_{s}=\frac{k \cdot I_{2}}{\sqrt{2}}=\frac{k \cdot E_{2}}{\sqrt{2} \cdot X} \cdot \tan \psi
$$

The $i_{s}(t)$ is absorbed by the dedicated filter $L_{2}-C_{2}$ tuned at frequency $f_{2}$ so that into the dc section that feeds the motor inverter flows the only continuous component $I_{d}$.

Referring to the control, a smart modulation [4] has been applied, where the input current follows a suitable sinusoidal reference in order to have a sinusoidal absorption, as explained in the following paragraph.

\section{Current Modulation}

In order to have a sinusoidal absorption the input current follows a suitable sinusoidal reference.

The AC reference current is obtained by multiplying the $\mathrm{AC}$ line voltage with a suitable equivalent conductance, in accordance with

$$
\underline{i}(t)=G \cdot \underline{v_{1}}(t)
$$

where $\underline{i}$ is the phasor of the AC phase current and $\underline{v_{1}}$ is the fundamental component of the $\mathrm{AC}$ contact line voltage.

The AC voltage contains the fundamental component and the component $v^{\prime \prime}$ corresponding to the perturbations present in the AC line (i.e. harmonics), the Park vector of the AC voltage being

$$
\underline{v}(t)=\underline{v_{1}}(t)+\underline{v^{\prime \prime}}(t)
$$

Thus, the instantaneous real power, expressed as Park vector, is given by

$$
\begin{aligned}
p(t) & =v_{a} \cdot i_{a}=\operatorname{Re}\left(\underline{v} \cdot i^{*}\right)=G \cdot \operatorname{Re}\left(\underline{v} \cdot v_{1}^{*}\right) \\
& =G \cdot v_{1}^{2}+G \cdot \operatorname{Re}\left(\underline{v}{ }^{\prime \prime} \cdot v_{1}^{*}\right)
\end{aligned}
$$

where $v_{1}^{*}$ is the complex conjugated value of $\underline{v_{1}}$.

Considering null power losses associated with the single phase converter, the $\mathrm{AC}$ - DC power balance is given by

$$
p(t)=\operatorname{Re}\left(\underline{v} \cdot v_{1}^{*}\right)=v_{D C} \cdot i_{D C}
$$

and the DC current, neglecting the ripple, can be expressed with

$$
\underline{v_{1}} i_{D C}=G \cdot \frac{\operatorname{Re}\left(\underline{v} \cdot v_{1}^{*}\right)}{v_{D C}}
$$

Considering the currents flowing through the DC bus, a non-linear relation between the DC voltage $v_{d c}$, the control variable $G$ and the load current $i_{\text {load }}$ is obtained

$$
\begin{aligned}
\frac{C}{2} \cdot \frac{d v_{D C}}{d t} & =i_{\text {load }}-G \cdot \frac{\operatorname{Re}\left(\underline{v} \cdot v_{1}^{*}\right)}{v_{D C}}= \\
& =i_{\text {load }}-G \cdot \frac{v_{1}^{2}}{v_{D C}}-G \cdot \frac{\operatorname{Re}\left(\underline{v}^{\prime \prime} \cdot v_{1}^{*}\right)}{v_{D C}}
\end{aligned}
$$

Since $V_{l}$ can be considered constant, the (17) can be linearized as follows:

$$
\begin{aligned}
& \frac{C}{2} \cdot \frac{d \Delta v_{D C}}{d t}=-\frac{V_{1}^{2}}{V_{D C}} \cdot \Delta G+G \cdot \frac{V_{1}^{2}}{V_{D C}^{2}} \cdot \Delta v_{D C}+d \\
& \text { where } d=\Delta i_{\text {load }}-G \cdot \frac{\operatorname{Re}\left(\underline{v^{\prime \prime}} \cdot v_{1}^{*}\right)}{V_{D C}}
\end{aligned}
$$

$d$ represents a perturbation, due to the $\mathrm{AC}$ line disturbances and the DC ripple.

For the DC voltage control, a proportional-integral (PI) controller has been chosen. Its transfer function is

$$
\Delta G=\left(k_{P}+\frac{k_{I}}{s}\right) \cdot F(s) \cdot \Delta v_{D C}
$$

where $F(\mathrm{~s})$ is the transfer function of the low pass filter required for reducing the $\mathrm{DC}$ bus ripple.

The Equations (18) and (19) constitute the closed loop of the DC voltage control that allows computing the values of the PI parameters. In a first approximation the transfer function $F(\mathrm{~s})$ can be neglected, obtaining

$$
\Delta v_{D C}(s)=\frac{s}{s^{2} \cdot \frac{C}{2}+s \cdot\left(k_{P}-\frac{G}{V_{D C}}\right) \cdot \frac{V_{1}^{2}}{V_{D C}}+k_{I} \cdot \frac{V_{1}^{2}}{V_{D C}}} \cdot d
$$

The denominator, considering a damping ratio of 0.707 , constrains the PI controller parameters to respect the following relations:

$$
k_{P}>\frac{G}{V_{D C}} \text { and } k_{I}=\left(k_{P}-\frac{G}{V_{D C}}\right) \cdot \frac{V_{1}^{2}}{V_{D C}} \cdot \frac{1}{C}
$$

\section{Model of the System}

In order to validate the theoretical analysis above described, a suitable model of the system has been implemented in the EMTP-ATP dynamic simulation tool. The data employed for the modelization refer to a real High Speed Train operating in Italy in $25 \mathrm{kV}-50 \mathrm{~Hz}$ lines. This 


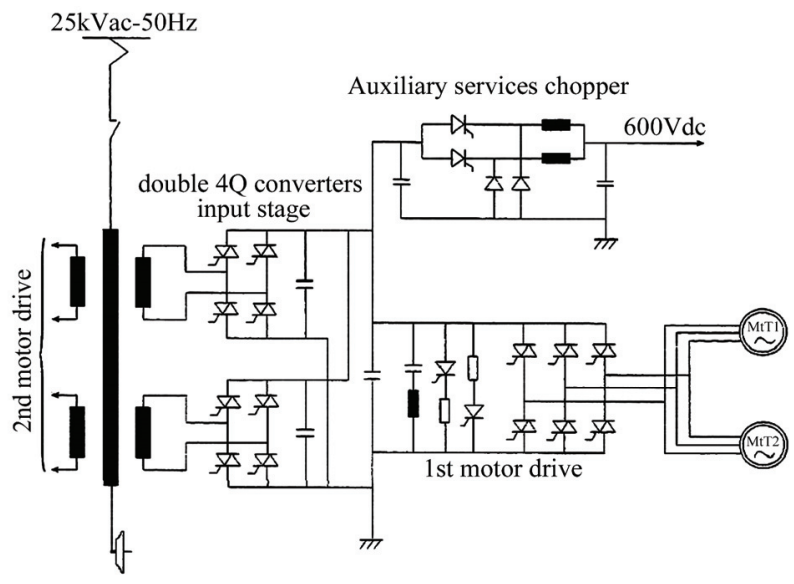

Figure 3. Traction circuit schematic diagram of the Italian high speed train

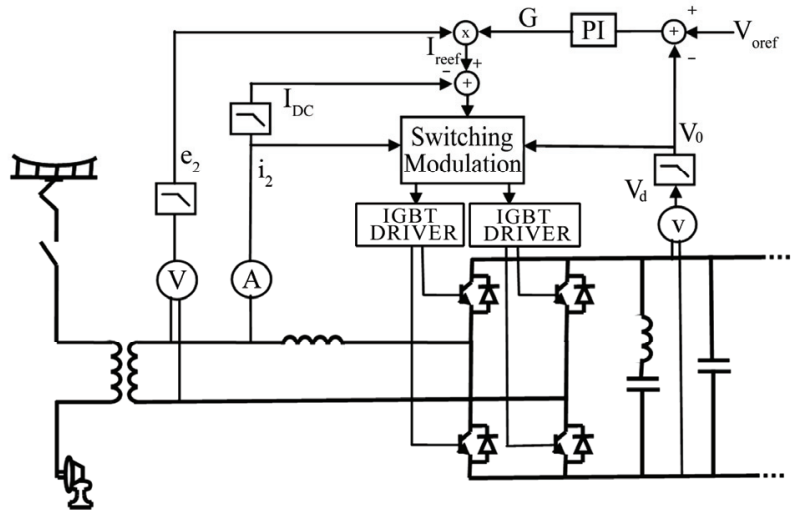

Figure 4. Block diagram of the implemented model of the system

vehicle is constituted by two locomotives with two motor drives each. Every motor drive is supplied by double 4Q converters input stage through the main transformer as depicted in Figure 3.

Each 4Q converter is sized for a rated power equal to $900 \mathrm{~kW}$ and a maximum peak power equal to $1500 \mathrm{~kW}$. These are relevant power values for a switching converter that has to be small and light enough to be installed onboard.

The 4Q converters are constituted by a power part and a control one. The power circuit has been modeled with the circuital elements already available in EMTP-ATP. The MODELS language has been used for implementing the proposed converter control.

The final schematic model is reported in Figure 4, where it is shown only one of the two input stage $4 Q$ converters.

In the block diagram represented in Figure 4 three control loops can be identified. The first one is the DC link voltage control loop constituted by the voltage measurement, the low-pass filter explained in the previ- ous paragraph, the comparison with the reference value $V_{\text {Oref }}$ and the PI controller. Its output is the value of the equivalent conductance $G$ that keeps the DC link voltage constant varying the power requested or injected by the traction motors and auxiliary services. The second loop is the reference current generator. It considers the input voltage measurement followed by a filter dedicated to the high frequency disturbances. The obtained value multiplied with the equivalent conductance $G$ gives the reference current that the converter, through the switching modulation, has to generate in order to balance the input and output powers. The third loop is related to the DC component compensation in the $\mathrm{AC}$ input current. In fact its output value is a constant current that, algebraically added to the reference one, allows to cancel the DC component avoiding the saturation of the input transformer.

\section{The Interlacing of the Converters}

The use of modulation techniques at constant frequency [5] lets an opportunely shifting of the switching time for the different 4Q converters onboard the train.

The final goal is to interlace more converters in order to diminish the harmonic content in the total absorbed current. The interlacing operation gives a shifting through the current waves coming out from the converters that have to be the one that minimize the harmonic content.

In order to preliminary study the benefit of the interlacing practice, two boost converters are considered. As reported in Figure 5, their current waves are shifted of a generic angle $\varphi$.

The two waves have the same duty cycle $\delta$ and they are only shifted of the angle $\varphi$. Therefore the Fourier series $f$ and $f^{\prime}$ of the two converters are the following:

$$
\begin{aligned}
& f(t)=A_{0}+\sum_{1}^{\infty}\left[A_{n} \cdot \cos (n \omega t)+B_{n} \cdot \operatorname{sen}(n \omega t)\right] \\
& f^{\prime}(t)=A_{0}+\sum_{1}^{\infty}\left[A_{n} \cdot \cos (n \omega t+n \varphi)+B_{n} \cdot \operatorname{sen}(n \omega t+n \varphi)\right]
\end{aligned}
$$

Applying the known trigonometric formula, the $f^{\prime}$ can be rewritten as:

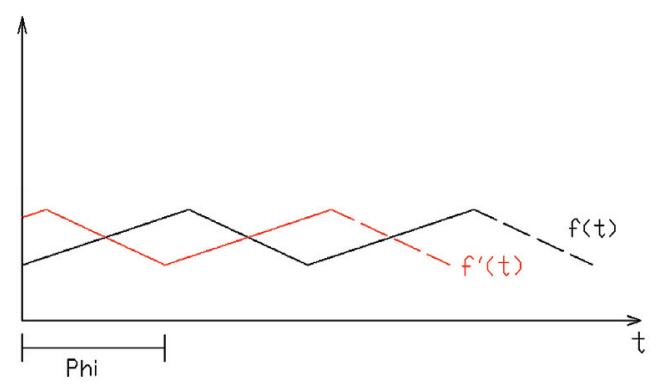

Figure 5. Waves shifting of the two interlaced boost converters currents 


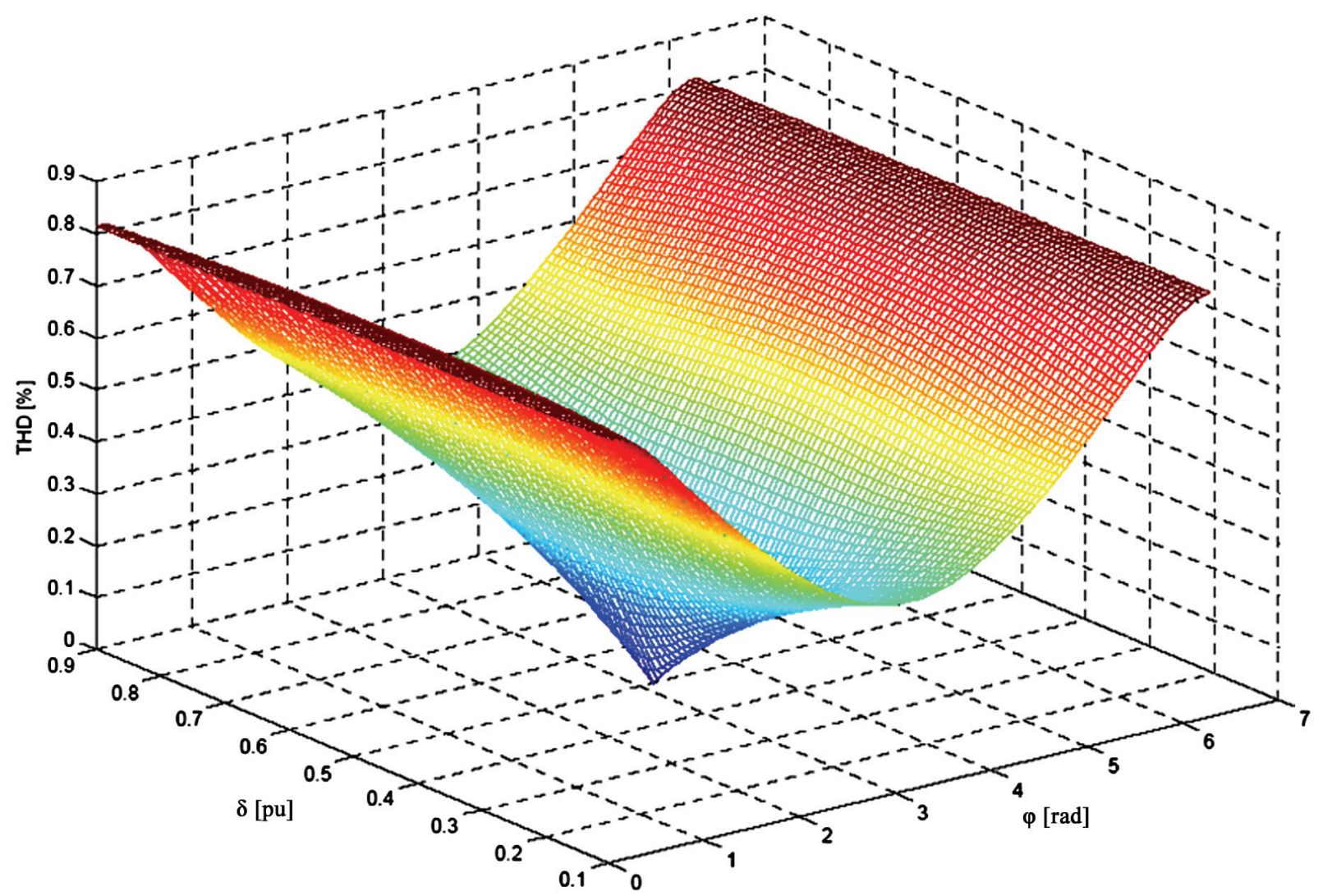

Figure 6. Behavior of the THD, varying the duty cycle $\delta$ and the shifting $\varphi$ between the currents absorbed by the two boost converters

Applying the known trigonometric formula, the $f^{\prime}$ can be rewritten as: where:

$$
f^{\prime}(t)=A_{0}+\sum_{1}^{\infty}\left[A_{n}{ }^{\prime} \cdot \cos (n \omega t)+B_{n}{ }^{\prime} \cdot \operatorname{sen}(n \omega t)\right]
$$

$$
\begin{aligned}
& A_{n}{ }^{\prime}=A_{n} \cdot \cos (n \varphi)+B_{n} \cdot \operatorname{sen}(n \varphi) \\
& B_{n}{ }^{\prime}=B_{n} \cdot \cos (n \varphi)-A_{n} \cdot \operatorname{sen}(n \varphi)
\end{aligned}
$$

Considering that the current absorbed by the train is the sum of the currents absorbed by the two converters, the resulting function to consider for the THD calculus is given by the sum of the two functions, that means:

$$
\begin{aligned}
f_{t}(t) & =f(t)+f^{\prime}(t)= \\
& =A_{0}{ }^{\prime}+\sum_{1}^{\infty}\left[A_{n}{ }^{\prime \prime} \cdot \cos (n \omega t)+B_{n}{ }^{\prime \prime} \cdot \operatorname{sen}(n \omega t)\right]
\end{aligned}
$$

with $A_{n}{ }^{\prime \prime}=A_{n}+A_{n}{ }^{\prime}$ and $B_{n}{ }^{\prime \prime}=B_{n}+B_{n}{ }^{\prime}$.

In this case the absolute THD is defined as following:

$$
T H D=\sqrt{\sum_{1}^{\infty} Z_{n}^{2}}
$$

with $Z_{n}^{2}=\left(A_{n}^{\prime \prime}\right)^{2}+\left(B_{n}^{\prime \prime}\right)^{2}$.

As it is possible to note, in the THD calculation the first harmonic has been also considered, referred to the switching frequency, because all the ripple is an undesirable component. The THD so calculated is function of the shifting angle $\varphi$ between the two waves and of the duty cycle $\delta$, here supposed the same for the two converters.

In order to underline the THD dependence from the parameters $\delta$ and $\varphi$, a simulation in Matlab environment has been carried out. The (22) has been considered, varying the duty cycle between 0.1 and 0.9 and the shifting between 0 and $2 \pi$ and supposing the current ripple amplitude equal to the $1 \%$ of the continuous component. The result is reported in Figure 6.

From Figure 6 it is possible to make some considerations. First of all, as expected, the THD is null for $\delta=0.5$ and $\varphi=\pi$, because it is the only case in which the two triangle waves are symmetric and in opposite phase, therefore all harmonics are cancelled.

From the optimal point, the THD initially grow fast, both varying $\delta$ and $\varphi$, underlining the fact that also small dissymmetry in the two converters switching diminish the advantages given by the interlacing. The optimal shifting $\varphi$ is always equal to $\pi$ and in this case the THD is always minor than the case of not interlaced converters $(\varphi=0)$.

Finally, the THD is directly proportional to the ripple amplitude respect to the DC component, and for this the 


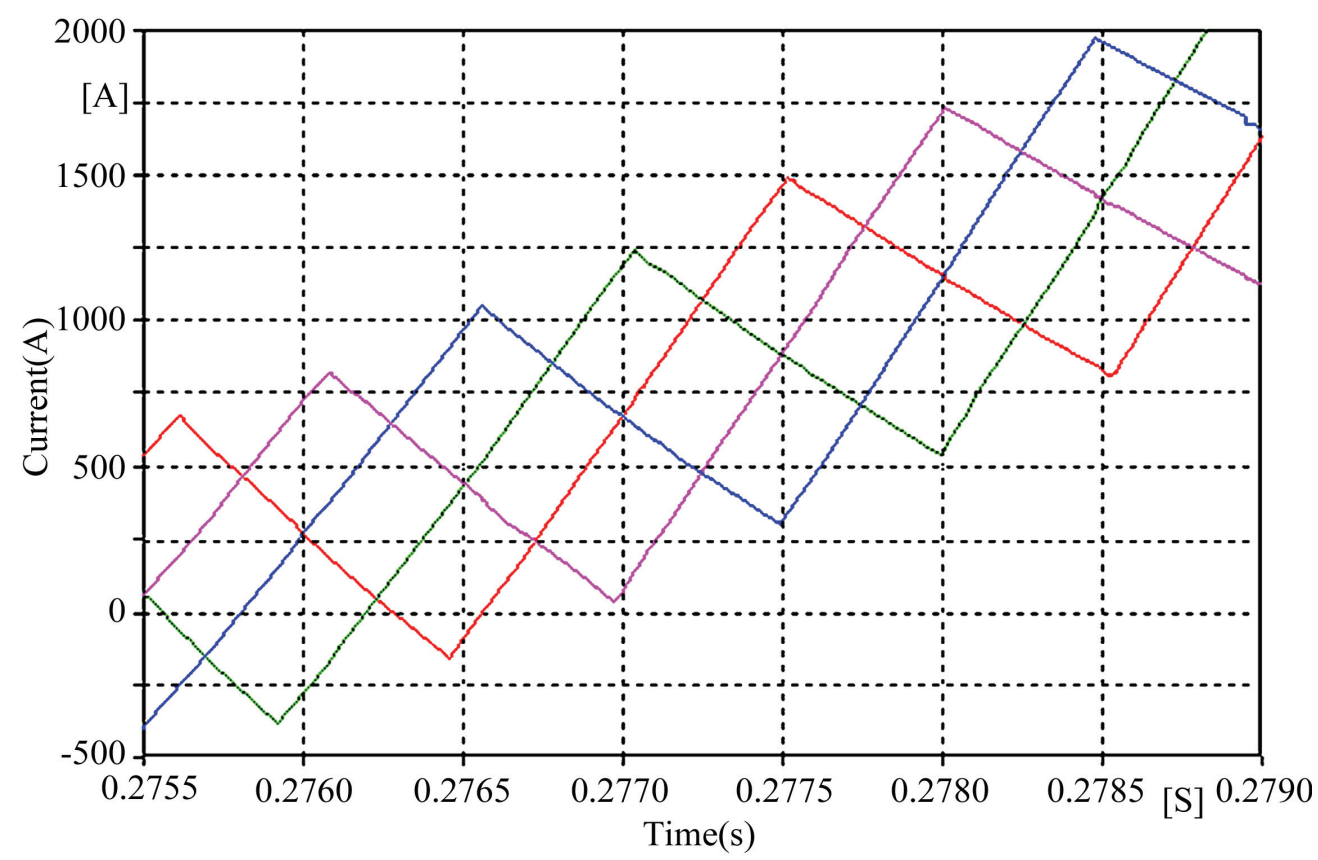

Figure 7. Shifting of the four switching frequencies

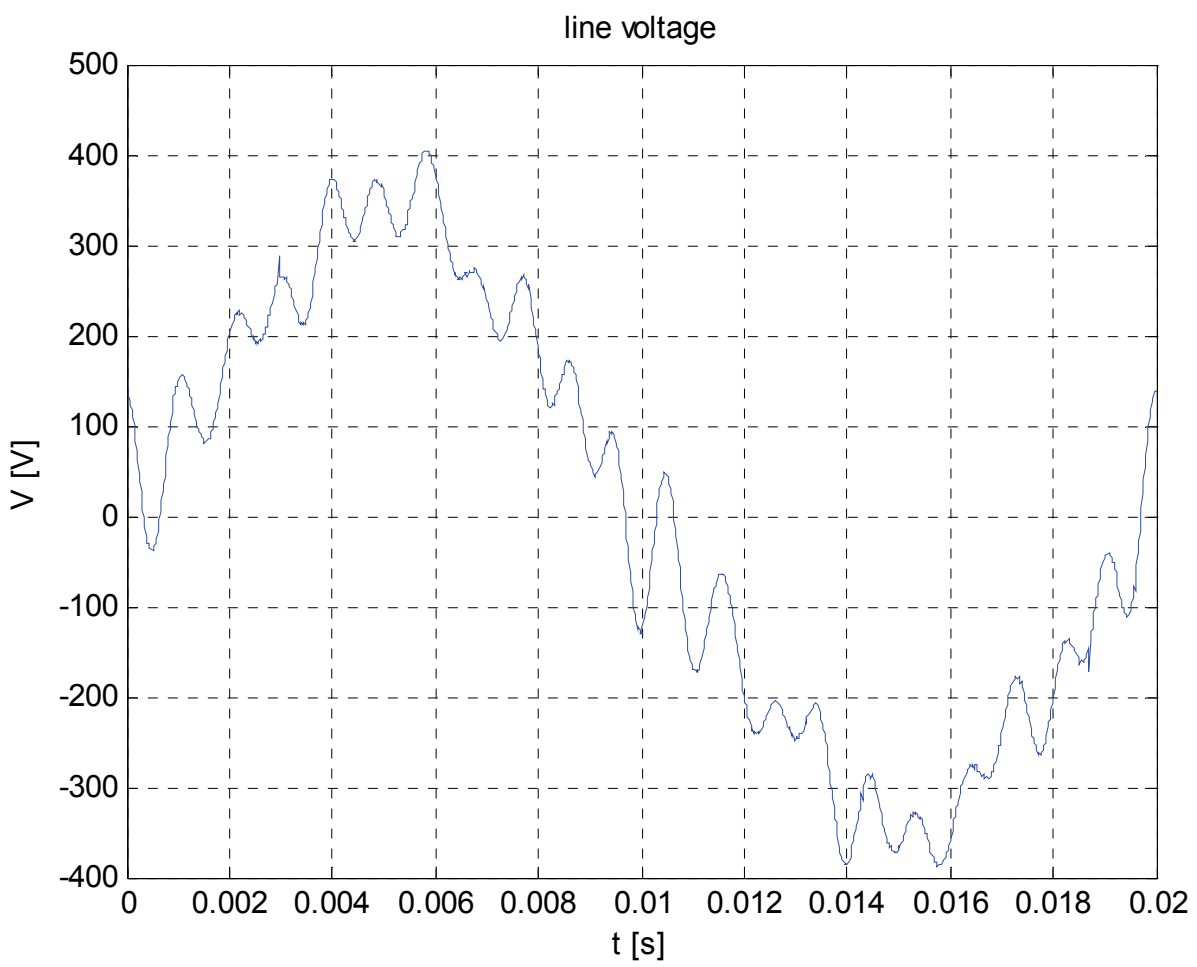

Figure 8. Line voltage waveform measured on the secondary side of an auxiliary transformer

effective values coming out from the practical cases are higher than the ones reported in Figure 6, considering the relevant current undulation due to the low switching frequencies.

Taking into account the different typologies of inter- operable locomotives and electro trains normally running on the railway lines, it is possible to note that after each input transformer there are 2 or $44 \mathrm{Q}$ converters. Each converter is supplied by a dedicated winding of the main transformer. 
It comes out that, in order to have a good interlacing, the shift of each converter switching frequency has to be respectively equal to $1 / 2$ or $1 / 4$ of the switching period.

In this way the ripple of the current absorbed by the transformer due to all the $4 \mathrm{Q}$ converters has the main frequency equal to two or four times the switching one with the advantages of a minor amplitude and easier filtration.

In Figure 7 is possible to note the shifting of the four switching frequencies.

Analyzing the smart modulation here applied, it is possible to note as the commutation instants are calculated starting from points on the reference current that have the same time distance. The interlacing can be easily obtained intercalating these time instants referred to the different converters.

\section{4Q Converters Model for Harmonic Analysis and Simulation Results}

In order to evaluate the harmonic contribution of the $4 \mathrm{Q}$ converters in single operation and in interlaced configuration, some numerical simulations are carried out, using ATP/EMTP program.

These converters are often supplied by a distorted input voltage, due to the low short circuit level of the railway lines and a greater harmonic content allowed by the dedicated standards. A typical waveform measured on the secondary side of the transformer for auxiliary services ins reported in Figure 8.

The most significant components are reported in Table 1.

This distortion is mainly due to the resonance phenomena along the line, also enhanced by the harmonic current injected by the trains. In order to have a correct operation of the $4 \mathrm{Q}$ converters it is necessary to have a cleaner input voltage obtained installing LC filters in the input stage. Moreover, the greater components $\left(>50^{\text {th }}\right)$ are carefully

Table 1. Harmonic content of the line voltage recorded during a measurements survey

\begin{tabular}{ccc}
\hline Harmonics Order & $\begin{array}{c}\text { Frequency } \\
{[\mathrm{Hz}]}\end{array}$ & $\begin{array}{c}\text { Harmonic Ampli- } \\
\text { tude [\%] }\end{array}$ \\
\hline 1 & 50 & 100 \\
3 & 150 & 7.14 \\
15 & 750 & 6.12 \\
19 & 950 & 5.1 \\
21 & 1050 & 12.76 \\
23 & 1150 & 3.06 \\
25 & 1250 & 5.1 \\
\hline
\end{tabular}

filtered to avoid interference with signaling system.

In this analysis, each $4 \mathrm{Q}$ converter has been studied considering the following characteristics:

- rated voltage of the contact line: $25 \mathrm{kV}, 50 \mathrm{~Hz}$;

- transformation ratio of the onboard transformer: $25 / 0.7 \mathrm{kV}$;

- DC link voltage: $1800 \mathrm{~V}$;

- rated power: $900 \mathrm{~kW}$;

- switching frequency: $500 \mathrm{~Hz}$.

The power components of the converter have been modeled with ideal switches, while the DC load with current generator. A negative value represents the current absorbed during the traction phase, while a positive one represents the regenerative braking.

In the controller are implemented two control loops.

The first one gives the value of conductance $G$ that multiplied by the input voltage determines the input current reference. The value of the equivalent conductance $G$ is obtained through PI controller comparing the measure of the DC link voltage with its reference in order to keep the DC voltage constant at its nominal value of $1800 \mathrm{~V}$. The function of this controller is to guarantee the equivalence between the input power and the one absorbed by the load. In order to assure a uniform power absorption among the various converters, there is only one regulator for all the converters.

The second loop is necessary to cancel the DC component in the $\mathrm{AC}$ current that can be generated by the low switching frequency of the switches. This DC components can be dangerous for the onboard transformer because can saturate the magnetic core. Indeed this transformer is not oversized due to the need to reduce its weight and volume. Therefore it is really sensible to the direct current component. Because the four $4 \mathrm{Q}$ converters are supplied by four independent transformer windings, it is necessary to adopt one of these regulators for each converter. In Figure 9 the current absorbed by one 4Q converter and its Fourier analysis are reported. It is possible to note a high ten order components corresponding to the switching frequency, but also an appreciable third harmonic. This last one is due to the difficulty to follow up the sinusoidal reference having a so low switching frequency.

The interlacing of the four converters has really reduced the harmonic content, as it is well represented in Figure 10, where the current absorbed at pantograph and its Fourier analysis are reported. In particular there are no more harmonics at the switching frequency, but there is still the third harmonic, due, as told before, to the low switching frequencies.

What told above is confirmed by Figure 11, where it is possible to note that there is a difficulty of the converter to switch at the end of each half period. 

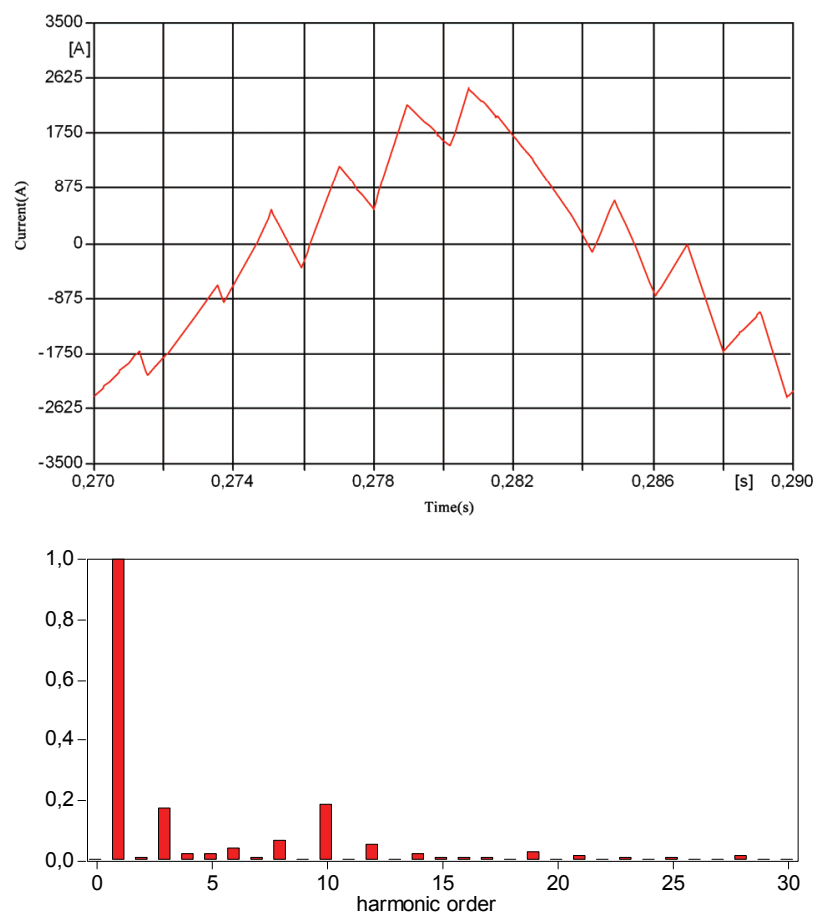

Figure 9. Current absorbed by one $4 Q$ converter and its Fourier analysis

In order to better evaluate the contribution of the four converters interlacing in improving the current waveform, the out of service of one converter has been considered. This condition can occur during the train operation.

The current absorbed at pantograph in this second case with only three 4Q converters working and its Fourier analysis are reported in Figure 12.

It is possible to note the worst harmonic content respect to the previous case and, most of all, the contribution of the switching frequency comes out again. In fact it is evident the presence of the ten order component. Regarding the third harmonic, the situation is not changed, always due to the low switching frequency.

In Figure 13 is reported the shifting of the three switching frequencies and also in this case it is evident the difficulty of the converter to switch at the end of each half period.

\section{Conclusions}

The paper deals with a power quality analysis regarding the input stage of the modern interoperable high speed trains constituted by more four quadrant $(4 \mathrm{Q})$ converters. In fact, the use of the $4 \mathrm{Q}$ converter allows to overcome the limits imposed by traditional rectifier.

However, the high power needed for the train acceleration, in the order of $6000 \mathrm{~kW}$ per locomotive, does not allow to have high switching frequencies. In fact, in the
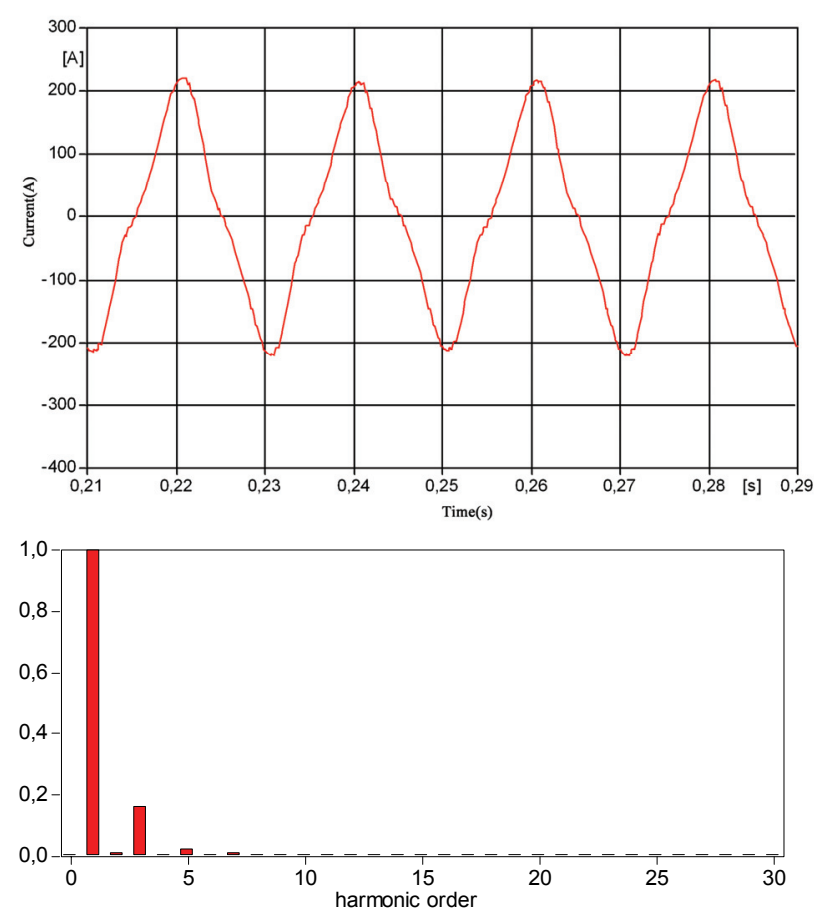

Figure 10. Current at pantograph in case of four $4 Q$ converters working and its Fourier analysis

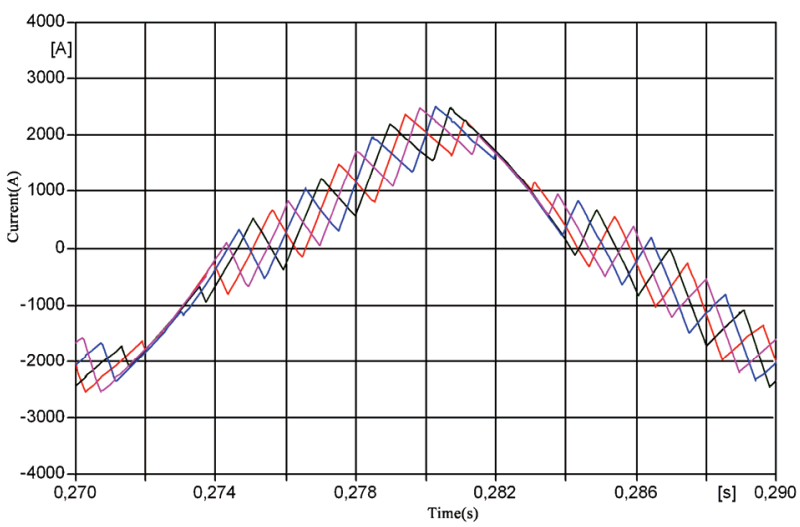

Figure 11. Currents absorbed by all the four $4 Q$ converter interlaced

recent realization they reach the maximum value of 500 $\mathrm{Hz}$. Consequently the absorbed current presents a high ripple value not always tolerable by the system.

The presence of more converters gives the opportunity, using dedicated control logics, to interlace them in order to reduce the harmonic content of the absorbed current at the pantograph.

Computer simulations have been carried out using a suitable model of more $4 \mathrm{Q}$ converters, for determining the contribution of the interlacing in improving the current waveform.

First, the case of four interlaced $4 \mathrm{Q}$ converters has 

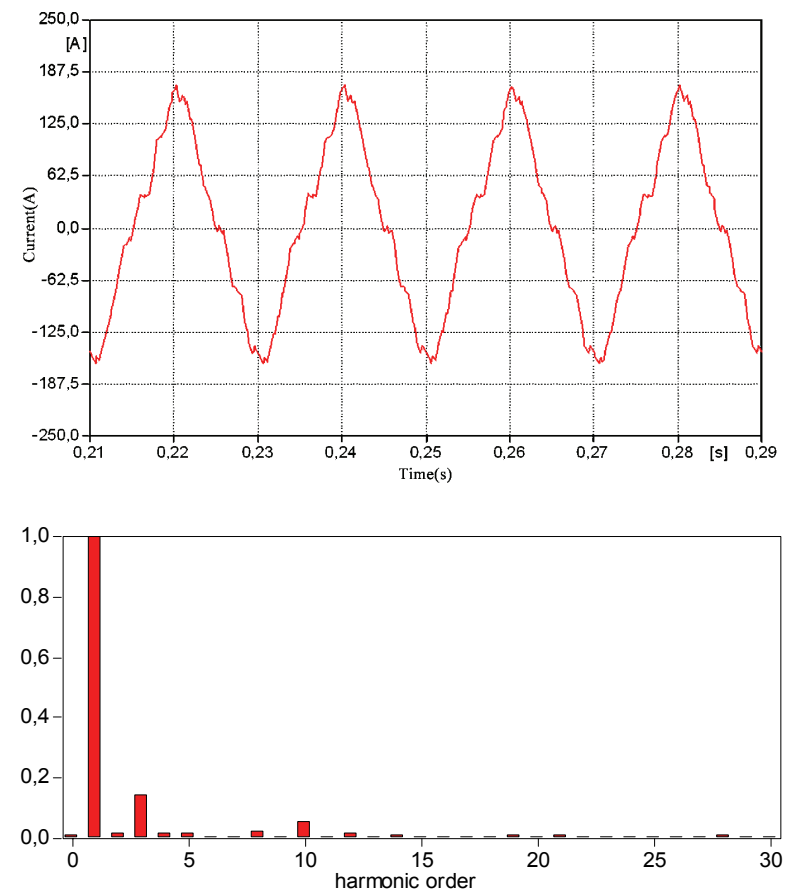

Figure 12. Current at pantograph in case of three $4 Q$ converters working and its Fourier analysis

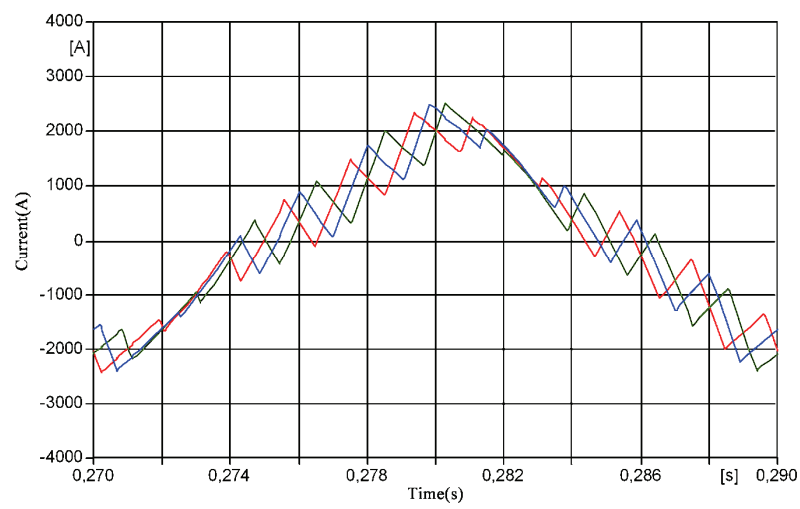

Figure 13. Currents absorbed by three $4 Q$ converter interlaced

been analyzed. In particular the analysis shows that the nterlaced operation allows the reducing of the absorbed current ripple, since the equivalent switching frequency is four times the single converter one. However the low harmonic components, such as the third one, cannot be canceled by this solution, therefore they have to be filtered by traditional LC passive filters.

The second case analyzed regards a condition that can occur during the train operation such as the out of service of one converter. In this situation the performances of the train are guarantee by the other three converters, even if it is not possible to completely cancel the harmonic component at the switching frequency.

\section{REFERENCES}

[1] G. W. Chang, H.-W. Lin, and S.-K. Chen, "Modeling characteristics of harmonic currents generated by high-speed railway traction drive converters," Transactions on Power Delivery, IEEE, Vol. 19, No. 2, pp. 766-773, April 2004.

[2] F. Perticaroli, "Electric systems for transportation," (in Italian), Casa Editrice Ambrosiana, Milano (Italy), January 2001 .

[3] M. Brenna, F. Foiadelli, G. C. Lazaroiu, and D. Zaninelli, "Four quadrant converter analysis for high speed trains," 12th International Conference on Harmonics and Quality of Power-ICHQP'06, Cascais, Portugal, 1-6 October 2006.

[4] M. S. Carmeli, F. Castelli Dezza, and G. Superti Furga, "Smart modulation: A new approach to power converter control," EPE'01, Graz, Austria, 27-29 Aug. 2001.

[5] M. S. Carmeli, F. Castelli Dezza, and G. Superti Furga, "Constant frequency current modulation algorithm based on linkage flux," PESC'03, Power Electronics Specialists Conference, Acapulco, Mexico, 15-19 June 2003.

[6] F. Foiadelli, G. C. Lazaroiu, and D. Zaninelli, "Probabilistic method for harmonic analysis in railway system," 2005 IEEE PES General Meeting, San Francisco (USA), 12-17 June 2004.

[7] P. Pinato and D. Zaninelli, "Harmonic disturbances in electric traction system overhead lines," IEEE X International Conference on Harmonics and Quality of Power, Rio De Janeiro (Brasil), 6-9 October 2002.

[8] W. Runge, "Control of line harmonics due to four-quadrant-converter in AC tractive stock by means of filter and transformer," in Proc. EPE'97, pp. 3.459-3.464, 1997.

[9] A. Capasso, R. Lamedica, R. Manigrasso, G. Sani, G. Superti Furga, and E. Tironi, "Reference power network for the harmonic propagation analysis," European Transactions on Electrical Power Engineering ETEP, Vol. 2, 1992.

[10] G. Burchi, F. Foiadelli, and D. Zaninelli, "Developments of power quality studies in electric transportation system," Electrical Power Quality and Utilisation, Journal, Vol. 6, No. 2, 2005.

[11] S. Burdett, J. Allan, B. Mellitt, and J. Taufiq, "A power factor and harmonic comparison of AC railway power electronic traction converter circuits," Fifth European Conference on Power Electronics and Applications, pp. 235-240, 13-16 Sep. 1993. 